\title{
An unexpected functional cause of upper airway obstruction
}

\author{
L. G. MICHELSEN AND A. F. L. VANDERSPF,
}

\begin{abstract}
Summary

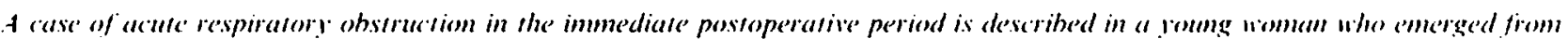

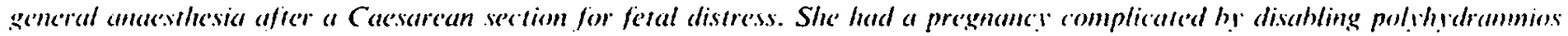

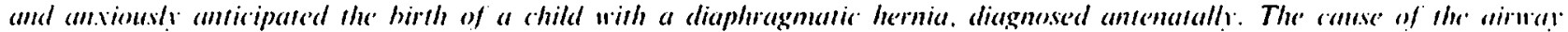

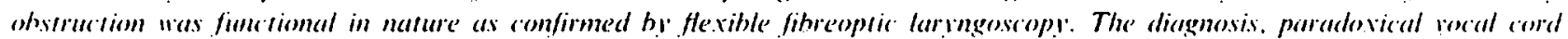

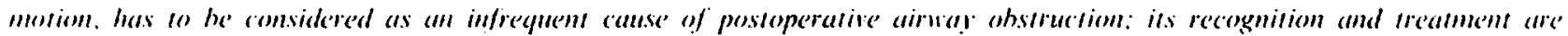

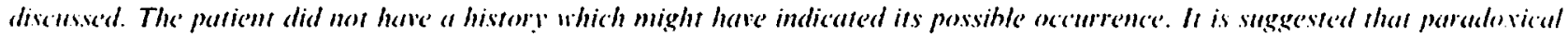

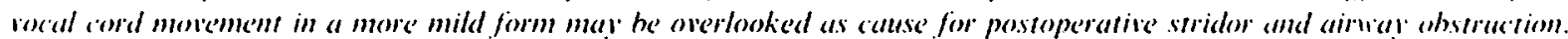

\section{Key words}

Complications: respirattory obstruction.

Acule upper alirwaly obstruction is a serious medical condition which requires prompt diagnosis and treatment. There is ustially an organic cause for the obstruction. but an increasing number of reports have documented casses without al definitc organic actiology.' "Paradoxical vocal cord molion. an abnormal motion of the vocal cords chatraclerised by their adduction during inspiration and abduction with exhalation. has been found in several of these patients. 2.s. The only reported case in the allacsthetic litcralure concerned it pattient with a longstanding history of respiralory symptomalology and previously documented episodes of paradoxical vacal cord movement who had persistent postoperallive stridor which required alcule inlervention and prolonged intensive care. ${ }^{*}$ We now present a cise of actite respiratory obstruction duc to the condition aller tracheal analesthesia in a previously healthy patient withoul al history of any respiratory illnesses.

\section{Case history}

4 26-yeall-old white female was translerred to the Universily Women's Hospital during her 35 th week of pregnancy with the diagnosis of incilpacitating polyhydramnios. Her medical history wals significant for one normal vaginal delivery and a dilatation and curettage performed under general anatesthesia. Both procedures were achicved without complications. She did not have a history of asthma. upper or lower respirallory tratcl inficitions or allergies. Fexcept for pregnancy and polyhydramnios. her physical examination was unremarkable. in particular with respect to her heild and neck. upper airwaty and pulmonary stattus. She was normotensive without ocdemal or other signs or symptoms of pre-cclampsia. Her prepregnant weight wats $68 \mathrm{~kg}$ while her weight at admission was $85 \mathrm{~kg}$. at a height of $1.60 \mathrm{~m}$.

An abdominal wliasound conlirmed the polyhydramnios. and in addition. revealed the presence of al keft diaphragemallic hernia in an approximaldy 36 -1leck-old lectus. An amniocentesis demonstrated an immatture lecilhin sphingomyelin (L S) ratlio. She wats kept in hospital and the delivery was delayed uncil extracorporeal membrane oxygenaltor support was atritiable and the fetal lungs had miltured. A mallure L.S ratio was present one week laller and an ammiotic callheter was sited. Amniotic huid was dranned slowly over a period of 8 hours. The next dily the pallicint had a spontancous rupture of membrancs and labour starled. Internill uterine and fetal heart rate monitors were placed. The labour became irregulat and dystuncilonal al which time an intravenous infusion of oxylocin was started Shortly after, late decelerations were noled on the letal heart rate tracing. The oxylocin was disconlinued and the pallemt was pul in the left lateral decubitus position. Oxygen was given by nasial cannula. A felal scialp pll wat 7.32. The patient was managed expectantly for the next 15

L.G. Michelsen. MD. Fellow in Anaesthesiology. A.F.L. VanDerSpck. MD. Assistant Professor of Anacsthesiology. The University of Michigan Medical Center. C.S. Molt Children's Hospital. Room C4139, Box 0800. Ann Arbor. Michigan 48109-0800. USA.

Correspondence should be addressed to: Dr A.F.L. VanDerSpek please.

Accepted 25 April 1988. 
minutes and the decelerations diminished. A repeat fetal scalp pH was 7.28; fetal distress was diagnosed and an urgent Caesarean section was undertaken.

The anxious patient was given sodium citrate $30 \mathrm{ml}$ by mouth and $100 \%$ oxygen by mask. General anaesthesia was induced in a 'rapid sequence' fashion with thiamylal $300 \mathrm{mg}$ and suxamethonium $100 \mathrm{mg}$ intravenously while cricoid pressure was maintained. The trachea was easily intubated with a $7.0 \mathrm{~mm}$ internal diameter, cuffed tracheal tube and anaesthesia was maintained with $50 \%$ nitrous oxide in oxygen and $0.5 \%$ halothane. The baby was delivered 5 minutes after induction; he appeared cyanotic, hypotonic, was not irritable and did not cry, but improved promptly after resuscitative measures. His Apgar scores were two and seven at 1 and 5 minutes respectively; the umbilical cord's venous blood pH was 7.33 . The mother was given morphine $10 \mathrm{mg}$ intravenously, and vecuronium $4 \mathrm{mg}$. The surgery proceeded uneventfully and finished 25 minutes later. General anaesthesia was discontinued and the muscle relaxant reversed with neostigmine $2.5 \mathrm{mg}$ and atropine $1.2 \mathrm{mg}$.

Her trachea was extubated when she was fully awake and her muscular strength had returned as determined by the presence of an adequate tidal volume, extremity movement, and head lift. She was transferred to a stretcher while breathing well. Upon turning her to the lateral decubitus position she developed stridor followed shortly by the cessition of ventilation and signs of upper airway obstruction. The awake patient appeared in obvious distress and grasped her throat with her hands. Neck extension, jaw lifting. the insertion of a nasopharyngeal airway, and attempted positive pressure ventilation applied by way of a mask failed to relieve the obstruction and establish ventilation; her lips and nail beds became cyanotic. Laryngospasm was suspected and she was given thiamylal $300 \mathrm{mg}$ and suxamethonium $100 \mathrm{mg}$. after which ventilation by mask was easy, while cricoid pressure was applied; her trachea was again intubated without difficulty with a 7.0$\mathrm{mm}$ cuffed tracheal tube. No anatomical abnormalities, forcign bodies, or oedema were noted during direct laryngoscopy. Ventilation was unimpeded with bilaterally clear breath sounds; her oxygen saturation, measured by a pulse oxymeter, was $99 \%$. She received $50 \%$ nitrous oxide in oxygen to keep her sedated until a transcutaneous nerve stimulator demonstrated the spontaneous, complete return of the train-of-four and a sustained tetanus at $100 \mathrm{~Hz}$.

The nitrous oxide was discontinued, and when she was awake and responding to commands with adequate muscle strength as determined by hand grip and neck lift, she was again extubated. She developed stridor immediately, which persisted despite manoeuvres including neck extension, jaw lift and positive airway pressure by mask. The patient sat up and improved only slightly. She alternated between severe stridor and mild to moderate dyspnoea over the next 15 minules. Her oxygen saluration remained at $98-99 \%$ on room air. however; she was able to speak intermittently in a weak hoarse voice, and affirmed to difficulty with breathing and to a 'foreign body' feeling in her throat. She was unable to cough. Lignocaine $100 \mathrm{mg}$ and hydrocortisone $100 \mathrm{mg}$ were given intravenously without any apparent effect. The otolaryngologists were consulted urgently and fibreoptic nasopharyngeal laryngoscopy was performed. This revealed paradoxical movement of her vocal cords with intermittent cpisodes of normal function. No foreign body, oedema, bleeding or other evidence of trauma was present. No attempl was made to pass the fibrescope beyond her vocal cords to avoid further compromise of her airway. The patient's varying degrec of respiratory difficulty, especially upon assuming the recumbent position, the inability to rule out subglottic abnormality, and her own request led to her re-intubation and sedation overnight. Ventilation was unassisted throughout the night. A chest $X$ ray demonstrated the tracheal tube to be in a satisfactory position; no pulmonary abnormalities were noted

A direct laryngoscopy and a bronchoscopy were performed under general anaesthesia the next day. No anatomical abnormalities, evidence of trauma, oedema, or infections were found. The pationt breathed well after extubation while sedated; however, once she was fully awake in the recovery room, she developed a mild stridor. which disappeared after the patient was given reassurance. An interview with her husband revealed that the patient had been very tense and anxious in the weeks preceding her operation because of difficulties experienced during pregnancy. There was no history of psychiatric problems or of previous episodes that would suggest a conversion disorder. The patient returned to the obstetric service and was discharged in good condition 4 days later.

\section{Discussion}

Upper airway obstruction from paradoxical vocal cord movement may resembic airway obstruction from other causes; it must be differentiated from laryngospasm, foreign body aspiration, vocal cord paralysis, allergic reactions. trauma, infection, oedema, and tumours. Patients with the condition have been trcated for uncontrollable asthma, anaphylaxis, laryngospasm, and vocal cord paralysis. Thus it is not surprising that several of the patients with this functional disorder have received aggressive therapy which included high dose steroids, tracheal intubation, and tracheostomy.4.5.7.8 The diagnosis is made by evaluation of vocal cord motion during an attack. Appropriate therapeutic manoeuvres may be applied before having to resort to drastic treatment once the correct diagnosis has been reached. Most of the cases of paradoxical vocal cord movement, confirmed by laryngoscopy, have responded to verbal support, placebo treatment, phonation therapy. or psychological support. ${ }^{5}$ Focused professional attention on the seriousness of the respiratory symptomatology of paradoxical vocal cord movement may magnify the symptoms as it reinforces the conversion reaction.

There appear to be several elements common to patients with this diagnosis. The majority have been women in the 18-50 age range who develop stridor or signs of upper airway obstruction, become tachypnoeic, contrary to what would be expected with an inspiratory obstruction, have a weak or absent voice, and are unable to cough. ${ }^{3.5}$ Arterial blood gases have been largely normal during attacks. ${ }^{3 . ?}$ The patients improved with the treatment described above, and psychological evaluation revealed a variety of psychiatric disorders with conversion elements. The patients are not consciously aware of the problem, and typically, cannot simulate the condition voluntarily. ${ }^{5.7}$ The episode in some of them had been preceded by an upper respiratory tract infection or a surgical procedure with general anaesthesia. This led Kellman and Leopold to suggest that the upper 
respiratory tract infection or tracheal intubation may direct at patient's attention to the larynx.

The case presented here has several of the common elements described previously, including age, sex, characteristics of the obstruction. laryngeal findings, and the response 10 verbal support. She experienced psychological stress in the immediate peripartum period, but she did not have a history of conversion reactions, psychiatric disorders. respiratory diseasc or paradoxical vocal cord movement. unlike a previous case described in conjunction with general anaesthesia." She had been under a significant amount of stress and it is indeed possible that the presence of a tracheal tube directed her attention to the larynx when she woke up after surgery. A complete psychological evaluation was not carried out. We were concerned about the potential for aspiration so the tracheal tube was kept in place until she was fully awake. The symptoms became apparent only after extubation. Sedative therapy with benzodiazepines or narcotics might have been a therapeutic alternative at that time, but sedation has had variable success and may latil and compromise the patient in the postoperative period. "s Intubation and extubation at a deep level of anaesthesia hats been advised in patients who have at history of the condition. ${ }^{*}$ However, once the patient energes from general anaesthesia. it may again present itself. Furthermore. als exemplified in this report, extubalion al a deep level of anaesthesia may not be advisable. We elected to re-intubate the patient as a temporary measure to allow for postoperative stabilisation and further evaluation.

Recently. we cared for a 31-year-old woman who presented for a diagnostic laparoscopy. She had a history of stridor which developed after a previous laparoscopy and subsided with oxygen delivery by mask, and verbal reassurance. The patient underwent an uneventful surgical procedure under general tracheal anaesthesia and was extubated at the end of the case. She developed stridor and became anxious and tachypneic upon arrival in the recovery room. but remained well oxygenated. She was able to speak in a weak voice. Paradoxical vocal cord movement was suspected. but fibreoptic laryngoscopy was not available to confirm the diagnosis. She was given verbal support with instructions to concentrate on the expiratory phase of her respiratory eycle. The stridor disappeared with these measures. It recurred 20 minutes later, and again responded to verbal support. The patient was discharged home the same day in good condition. We suspect that this case was also caused by paradoxical vocal cord movement. even though we were unable to confirm it.

In milder forms the problem may be overlooked and be more common than generally acknowledged. If this is true. anaesthetists are likely to see paticnts with paradoxical vocal cord movement. Thus it should be considered in the differential diagnosis of postoperative stridor and respiratory obstruction; an increased awareness of this disorder should help to treal it correctly. However. the diagnosis should only be made after other causes of airway obstruetion have been ruled out and the characteristic findings identified at laryngoscopy. We suggest further that if verbal reassurance and placebo intramuscular injections fail to relieve the symptoms. the administration of antipsychotic medications (haloperidol. droperidol) may also be considered in the acute phase as a temporaty measure.

\section{References}

1. Pattroson R. Somatz M. Ilorion M. Munchitusen stridor: non-organic laryngeal obstruction. Clinical fltory 1974: 4: 30710.

2. Rogitrs JII. Strle PM. Paradoxical movement of the bocal

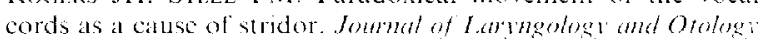
1978:92: 1578

3. Cormir YR. Cames P. Dismle lis MI Non-organic aleute upper arway obstruction: Description and a diagnostic approach Amerater Revien of Respiratom Disease 1980: 121: 14750

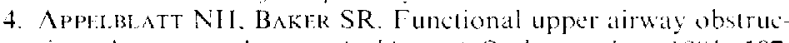
lion: A new syndrome. Archiles of Otolaryengeg 1981: 107: 3056 .

5. Krilmani RM. Lmomolo DA. Paradoxical cord motion: An important cause of stridor. I-colmescome 1982: 92: 58 60.

6. Katian M, Brit-Zvi Z. Stridor caused by vocal cord mallunction associated with emotional factors. Clinical Pediatricis (Philadelphia) 1985:24: 158:60.

7. Christophtr KL. WoOd RP. Eckekt C. Blager FB. RaNey RA. Solmrado JF. Vocal cord dystunction presenting as asthma. New England Journal of Medicine 1983: 308: 1566 70

8. Hammer G. Schwiñ D. Wold Mar H. Postoperative complications duc to paradoxical vocal cord motion. Anesheriolose 1987: 66: 6867 